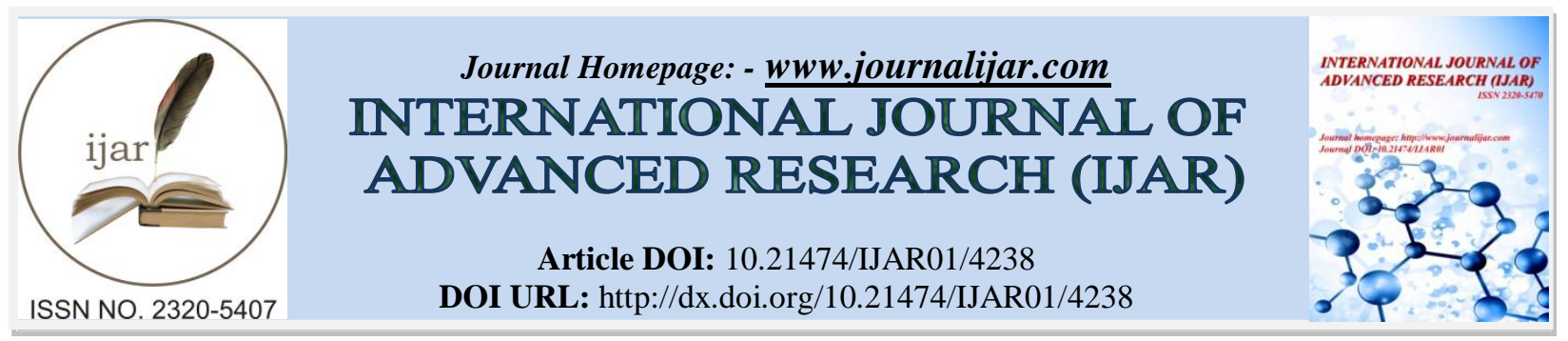

RESEARCH ARTICLE

\title{
A SURVEY ON BULK TRANSPORTATION PROBLEM.
}

Sungeeta Singh $^{1}$, Sudhir Chauhan ${ }^{2}$ and Kuldeep Tanwar ${ }^{1}$.

1. Department of Mathematics, Amity University, Gurgaon, Haryana, India

2. Department of Mathematics, Amity School of Engineering and Technology, Bijwasan, New Delhi, India.

\section{Manuscript Info}

Manuscript History

Received: 21 March 2017

Final Accepted: 24 April 2017

Published: May 2017

Key words:-

Bulk Transportation problem, Pareto Optimal, Cost-Time Trade-Off, Branch and Bound, Lexi-Search, Pattern

Recognition, Non Convex.

\section{Abstract}

Bulk Transportation problem(BTP) is a special type of transportation problem having wide industrial applications.In a BTP the requirement of each destination has to be met from only one source; however, subject to the availability of a commodity, a source can supply to any number of destinations. The paper presents an outline survey of the methods used in solving a BTP. The paper is motivated by the importance of BTP and the need for researchers to be acquainted with all existing methods in order to solve such problems or develop new improved heuristic methods.

Copy Right, IJAR, 2017,. All rights reserved.

\section{Introduction:-}

The classical transportation problem consists of ' $\mathrm{m}$ ' sources each producing a finite available units of a certain commodity and ' $n$ ' destinations each having finite demand of that commodity. However, in a BTP the supply of finite available units of a certain commodity from ' $m$ ' sources to ' $n$ ' destinations is restricted by the condition that the demand of any destination must be fulfilled from only one source.Further, subject to the availability of the commodity a source may supply to any number of destinations. In a BTP, a bulk transportation cost is assigned from each source to each destination. The additional condition named as bulk arises often in practical situations. BTP has a lot of applications in the areas where demand is required to be fulfilled from a single source such as the vehicle routing problems, the scheduling and facility location problems, assigning software development programs to computer programmers, fixed charge source location models in which customer's demand must be fulfilled by a single source.

The specific BTPs studied by researchers are the single criterion BTP, Multi-Criteria BTP, Multi-Index BTP and Non Convex BTP.. In single criterion BTP, there is only one objective to minimize the total cost or the total time of transportation. In a Multi-Criteria BTP, there is more than one objective such as minimization of cost, time and deterioration of goods during transportation etc. In a Multi-Index BTP, there are more than two indices such as source, destination, different types of commodities, modes of transportation and facilities etc.

Section 2 deals with the Single criterion BTP;the single criterion being the cost or time.Section3 presents the Bi Criteria BTP and the work done therein.In Section 4 the Multi-Index BTP is considered and the contributions are highlighted.Section 5 briefly deals with the Non Convex BTP.Section 6 concludes the paper. 


\section{Single Criterion Bulk Transportation Problem:-}

A single criterion BTP involves only one criterion vis. Cost or Time,The objective of the BTP is thus to minimize cost or to minimize time;the former is known as the Cost minimizing BT while the latter is called the Time minimizing BTP.

\section{Cost Minimizing Bulk Transportation Problem:-}

Cost Minimizing BTP was formulated by Maio and Roveda [9] with the objective of minimizing the total cost of bulk transportation. In this BTP the requirement of each destination is to be satisfied from only one source. However, a source can supply to any number of destinations according to the availability of the commodity.

Here the number of sources and destinations are ' $\mathrm{m}$ ' and ' $\mathrm{n}$ ' respectively. The entire requirement of a destination is met from one source alone, however, a source can supply to any number of destinations.

\section{The mathematical formulation of the cost minimizing bulk transportation problem is as follows:}

\section{Minimize}

$$
C=\sum_{i=1}^{m} \sum_{j=1}^{n} c_{i j} x_{i j}
$$

subject to the constraints

$\sum_{j=1}^{n} b_{j} x_{i j} \leq a_{i}(i=1,2, \ldots, m)$

$\sum_{i=1}^{m} x_{i j}=1(j=1,2, \ldots, n)$

$x_{i j}=0$ or $1(i=1,2, \ldots, m ; j=1,2, \ldots n)$.

where $a_{i}(\mathrm{i}=1,2,3, \ldots, \mathrm{m})$ is the number of units of a commodity available at source $\mathrm{i}, b_{j}(\mathrm{j}=1,2,3, \ldots, \mathrm{n})$ is the units of commodity required at destination $\mathrm{j}, c_{i j}(\mathrm{i}=1,2, \ldots, \mathrm{m} ; \mathrm{i}=1,2, \ldots ., \mathrm{n})$ is the per unit cost of bulk transportation of the commodity from source $\mathrm{i}$ to destination $\mathrm{j}$ and $x_{i j}(\mathrm{i}=1,2, \ldots, \mathrm{m} ; \mathrm{j}=1,2, \ldots, \mathrm{n})$ the variable assuming the value 1 or 0 according to whether the requirement of destination ' $\mathrm{j}$ ' is met from source ' $\mathrm{i}$ ' or not.Also, $a_{i}^{\prime} s, b_{j}^{\prime} s$ and $c_{i j}^{\prime} s$ are all non-negative real values and $\mathrm{C}$ denote the total cost of bulk transportation.

Maio and Roveda [9] presented a solution procedure based on zero- one implicit enumeration. The main drawback of their algorithm is that a lot of calculations are involved for checking the feasibility of the solution and several solutions have to be recorded till the optimal solution is identified.

An algorithm comprising of two phases for solving this problem is proposed by Srinivasan and Thompson [18]. The problem is converted into a different transportation problem whose basic feasible solution is the optimum solution of the actual problem. In the first phase, the problem is solved by ignoring the constraints while in the second phase, a branch and bound technique is used to obtain a unique solution. The proposed algorithm is more efficient when the number of destinations exceeds the number of sources by a large number.Murthy [10] proposed a method based on lexicographic search for solving cost minimizing bulk transportation problem. Solutions are generated as a string of numbers systematically,in some hierarchy of their values.

Verma and Puri [19] considered the cost minimizing bulk transportation problem and proposed a method based on the branch and bound technique.

\section{Time Minimizing Bulk Transportation Problem:-}

In this section, a single criterion time minimizing BTP is discussed. The single criterion here is time instead of cost as discussed in the preceeding subsection and consequently the objective is to minimize the total time ' $\mathrm{T}$ 'of the BTP.

Here ' $m$ 'and ' $n$ ' denotes number of sources and destinations respectively. The entire requirement of a destination is met from one source only; but a source can supply to any number of destinations.

The mathematical formulation of the time minimizing bulk transportation problem is as follows:

Minimize

$T=\max \left\{i_{i j}: x_{i j}=1\right\}$

subject to the constraints

$$
\sum_{j=1}^{n} b_{j} x_{i j} \leq a_{i}(i=1,2, \ldots, m)
$$


$\sum_{i=1}^{m} x_{i j}=1(j=1,2, \ldots, n)$
$x_{i j}=0$ or $1(i=1,2, \ldots, m ; j=1,2, \ldots n)$

where $a_{i}(\mathrm{i}=1,2,3, \ldots, \mathrm{m})$ is the available units of a product available at source $\mathrm{i}, b_{j}(\mathrm{j}=1,2,3 \ldots, \mathrm{n})$ is the units of a product required at destination $\mathrm{j}, t_{i j}(\mathrm{i}=1,2, \ldots, \mathrm{m} ; \mathrm{j}=1,2, \ldots, \mathrm{n})$ is the bulk transportation time of the product from source $\mathrm{i}$ to destination $\mathrm{j}$ and $x_{i j}(\mathrm{i}=1,2, \ldots, \mathrm{m} ; \mathrm{j}=1,2, \ldots, \mathrm{n})$ the variable assuming the value 1 or 0 according as the requirement of destination $\mathrm{j}$ is met from source $\mathrm{i}$ or not. $a_{i}^{\prime} s, b_{j}^{\prime} s$ and $t_{i j}^{\prime} s$ are non-negative real values and $\mathrm{T}$ is the total time of bulk transportation.

A new method for obtaining an initial basic feasible solution of zero-one time minimizing transportation problem is proposed by Bhatia [3]. The initial feasible solution is improved step by step until an optimal solution is obtained. The proposed method is also helpful in checking the feasibility of the problem.

Foulds and Gibbons [5] proposed two methods for The Bulk, Zero-One Time Mini-Max Transportation Model. One method was based on branch and bound method and other was based on backtracking technique. A comparison between the two proposed methods showed that the branch and bound method provides better results as compared to backtracking technique

\section{Bi-Criteria Bulk Transportation Problem:-}

Bi-Criteria BTP is a type of bulk transportation problem with two objectives of minimizing the total cost and minimizing the total time of transportation. Here, as there are two criteria cost and time which are to be minimized,the optimum solution can only be a trade off between the two.Thus, here Pareto Optimal efficient pairs are obtained as the solution pairs.

The mathematical formulation of a Bi-criteria BTP is

Minimize

$$
C=\sum_{i=1}^{m} \sum_{j=1}^{n} c_{i j} x_{i j}
$$

$T=\max \left\{t_{i j} x_{i j}: i=1,2, \ldots, m ; j=1,2, \ldots, n\right\}$

subject to the constraints

$\sum_{j=1}^{n} b_{j} x_{i j} \leq a_{i}(i=1,2, \ldots, m)$

$\sum_{i=1}^{m} x_{i j}=1(j=1,2, \ldots, n)$

$x_{i j}=0$ or $1(i=1,2, \ldots ., m ; j=1,2, \ldots n)$

where $\mathrm{m}$ and $\mathrm{n}$ denotes number of sources and destinations respectively and $a_{i}(\mathrm{i}=1,2,3, \ldots, \mathrm{m})$ be the units of commodity available at source $\mathrm{i}, b_{j}(\mathrm{j}=1,2,3 \ldots, \mathrm{n})$ the units of commodity required at destination $\mathrm{j}, c_{i j}(\mathrm{i}=1,2, \ldots, \mathrm{m}$; $\mathrm{i}=1,2, \ldots \ldots, \mathrm{n})$ the units of cost of bulk transportation of the commodity from source $\mathrm{i}$ to destination $\mathrm{j}, t_{i j}$ $(\mathrm{i}=1,2, \ldots, \mathrm{m} ; \mathrm{j}=1,2, \ldots, \mathrm{n})$ the unit of time of bulk transportation of the commodity from source $\mathrm{i}$ to destination $\mathrm{j}$, and $x_{i j}(\mathrm{i}=1,2, \ldots, \mathrm{m} ; \mathrm{j}=1,2, \ldots, \mathrm{n})$ the variable assuming the value 0 or 1 according as the entire requirement of destination $\mathrm{j}$ is to met or met from source $\mathrm{i}$. All the parameters $a_{i}^{\prime} s, b_{j}^{\prime} s, c_{i j}^{\prime} s$ and $t_{i j}^{\prime} s$ are free to take any non-negative real values. Let $\mathrm{C}$ and $\mathrm{T}$ denote the total cost and duration of bulk transportation respectively.

Prakash and Ram [14] proposed a solution for the Bi- Criteria BTP with the objectives of minimizing the cost and duration of transportation as primary and secondary objectives. . In the proposed method, priority factors are used to convert the Multi Objective BTP into a single objective BTP.

Gupta et al. [6] studied cost-time trade-off relations in BTP which further generated a sequence of efficient cost-time pairs using which the decision maker has a flexibility in decision making by choosing the appropriate efficient pair.

A variety of BTP were studied by Bhavani [4]. Prakash et al. [13] proposed two methods, one based on branch and bound technique and the other based on preemptive priority factors for solving the cost- time BTP with the objective of minimizing the total cost and duration of BTP without priorities. They proposed two algorithms to get the Pareto Optimal solutions or Cost time trade off pairs. They studied the problem of Prakash and Ram [14] wherein the priorities were not assigned to the objectives. A comparison between the two proposed methods is also shown and it is shown that the algorithm using preemptive priority factors takes less time as compared to the algorithm based on the branch and bound technique. 
Prakash et al. [16] proposed the Extremum Difference Method to obtain the Pareto Optimal solutions of the costtime trade-off BTP. .

Prakash et al. [15] proposed a method based on the lexicographic minimum to obtain Pareto Optimal solutions of the cost-time BTP,by considering a sequence of prioritized bi-criterion BTPs whose solution gives the set of Pareto Optimal solutions of the actual problem. Lexicographic minimum is used to solve the prioritized Bi-criteria bulk transportation problems.

Multi-Index Bulk Transportation problem:-

Multi-Index BTP is an extension of bulk transportation problem which involves transporting different types of commodities through various modes of transportations like truck, rail, ship etc. having multiple sources and multiple destinations. The objective of the problem is to find the minimum bulk transportation cost.

Here, there are ' $m$ ' sources each producing ' $p$ ' commodities, ' $n$ ' destinations and ' $k$ ' facilities . The bulk transportation cost from a source ' $i$ ' to the destination ' $j$ ' at a given facility ' $k$ ' is $C(i, j, k)$. Let $S(i, p)$ denote the number of units of $p$ th commodity available at source ' $i$ ' and $D(j, p)$ denote the number of units of $p t h$ commodity required at destination ' $j$ '.

Further, $D^{1}(i, p)$ denotes the number of units of $\mathrm{p}^{\text {th }}$ commodity supplied from ith plant to some destination. $D^{1}(j, p)$ denotes the number of units of the $\mathrm{p}^{\text {th }}$ commodity supplied to $\mathrm{j}^{\text {th }}$ destination from some source.

The mathematical formulation of the Multi-Index BTP is as follows:

Minimize

$\mathrm{Z}=\sum_{i=1}^{m} \sum_{j=1}^{n} \sum_{k=1}^{l} C(i, j, k) X(i, j, k)$

subject to the constraints

$$
\begin{array}{ll}
\sum_{j=1}^{n} \sum_{k=1}^{l} D^{1}(j, p) X(i, j, k) \leq S(i, p), & \text { for all } i, p \\
\sum_{i=1}^{m} \sum_{k=1}^{l} D^{1}(i, p) X(i, j, k)=D(j, p), & \text { for all } j, p \\
X(i, j, k)=0 \text { or } 1 &
\end{array}
$$

Constraint(1) represents the total cost of the bulk supply of the commodities from source ' $\mathrm{i}$ ' to destination ' $\mathrm{j}$ ' availing facility ' $k$ '. Constraint (2) shows that a source can supply its commodities to more than one destinations while constraint (3) shows that a destination may get its requirement from more than one plant respectively. If constraint (4) has value 1, then commodities are supplied from source ' $i$ ' to destination ' $j$ ' availing facility ' $k$ ' else not.

Babu and Murthy [2] developed a Lexi-Search algorithm for solving a variant BTP. He showed that Lexi-Search algorithm is more efficient than the Branch and Bound method.

Purosotham and Murthy [17] proposed a Lexi-Search algorithm based on pattern recognition technique with the objective of minimizing the cost of multi-product BTP .

Latha $[7,8]$ proposed a method to solve a Multi commodity BTP and a three dimensional time minimization BTP by formulating the model into a zero-one programming problem and solving it by the pattern recognition techniques coupled with the Lexi-search approach.

Naganna[11],Naganna and Murthy [12] proposed a method to solve time dependent multi-index BTP through a Lexi-Search algorithm based on Pattern recognition technique.

\section{Non Convex Bulk Transportation Problem:-}

Arora and Ahuja [1] proposed a method for solving non convex BTP. A fractional BTP was formed by the authors whose feasible solution was used to find the optimal solution of the non convex BTP. Parametric programming was used to obtain the feasible solution of the fractional BTP. 


\section{Conclusion:-}

The present survey is done to acquaint the reader with the BTP its genesis and application as well as the methods outlined in solving a BTP and its extensions. The authors hope that the present survey will be beneficial to researchers in providing new insights to solve a BTP and its extensions, which in turn,may lead to the development of new and possibly simpler methods to solve BTPs and its extensions. The existing methods in literature to solve a BTP are rather lengthy and time consuming.

Table 1:- Contributions in Bulk Transportation Problem

\begin{tabular}{|c|c|c|c|}
\hline & Author & Type of BTP & Contribution \\
\hline 1. & Maio and Roveda [9] & Cost BTP & $\begin{array}{l}\text { A solution procedure based on zero- one } \\
\text { implicit enumeration is developed. }\end{array}$ \\
\hline 2. & Srinivasan and Thompson [18] & Cost BTP & $\begin{array}{l}\text { An algorithm comprising of two phases for } \\
\text { solving this problem is proposed.In the } \\
\text { second phase Branch and Bound procedure is } \\
\text { used }\end{array}$ \\
\hline 3. & Murthy [10] & Cost BTP & $\begin{array}{l}\text { A lexicographic search based method is } \\
\text { proposed. }\end{array}$ \\
\hline 4. & Verma and Puri [19] & Cost BTP & $\begin{array}{l}\text { A method based on branch and bound } \\
\text { technique is proposed. }\end{array}$ \\
\hline 5. & Bhatia [3] & Time BTP & $\begin{array}{l}\text { A new method for obtaining an initial basic } \\
\text { feasible solution of time minimizing BTP is } \\
\text { proposed which is improved step by step } \\
\text { until an optimal solution is obtained. }\end{array}$ \\
\hline 6. & Foulds and Gibbons [5] & Time BTP & $\begin{array}{l}\text { Two methods for the Time Minimizing BTP } \\
\text { based on branch and bound method and } \\
\text { backtracking technique are proposed. }\end{array}$ \\
\hline 7. & Prakash and Ram [14] & $\begin{array}{l}\text { Cost-Time } \\
\text { BTP }\end{array}$ & $\begin{array}{l}\text { Priority factors are proposed to convert the } \\
\text { Multi Objective BTP into a single objective } \\
\text { BTP }\end{array}$ \\
\hline 8. & Gupta et al. [6] & $\begin{array}{l}\text { Cost-Time } \\
\text { BTP }\end{array}$ & $\begin{array}{l}\text { Studied cost-time trade-off relations in BTP } \\
\text { which further generated a sequence of } \\
\text { efficient cost-time pairs }\end{array}$ \\
\hline 9. & Bhavani [4] & $\begin{array}{l}\text { Cost-Time } \\
\text { BTP }\end{array}$ & A variety of BTPs were studied \\
\hline 10. & Prakash et al. [13] & $\begin{array}{l}\text { Cost-Time } \\
\text { BTP }\end{array}$ & $\begin{array}{l}\text { Two methods, one based on branch and } \\
\text { bound technique and the other on preemptive } \\
\text { priority factors, were proposed. }\end{array}$ \\
\hline 11. & Prakash [14] & $\begin{array}{l}\text { Cost-Time } \\
\text { BTP }\end{array}$ & $\begin{array}{l}\text { Priority factors are used to convert the Multi } \\
\text { Objective BTP into a single objective BTP. }\end{array}$ \\
\hline 12. & Prakash and Ram [15] & $\begin{array}{l}\text { Cost-Time } \\
\text { BTP }\end{array}$ & $\begin{array}{l}\text { A method based on the lexicographic } \\
\text { minimum is proposed. }\end{array}$ \\
\hline 13. & Prakash et al. [16] & $\begin{array}{l}\text { Cost-Time } \\
\text { BTP }\end{array}$ & $\begin{array}{l}\text { Extremum Difference Method is proposed to } \\
\text { obtain the Pareto Optimal solutions of the } \\
\text { cost-time trade-off BTP. }\end{array}$ \\
\hline 14. & Babu and Murthy [2] & $\begin{array}{l}\text { Multi -Index } \\
\text { BTP }\end{array}$ & $\begin{array}{l}\text { A Lexi-Search algorithm for solving a variant } \\
\text { BTP is proposed and is shown as more } \\
\text { efficient than Branch and Bound Method. }\end{array}$ \\
\hline 15. & Purosotham and Murthy [17] & $\begin{array}{l}\text { Multi -Index } \\
\text { BTP }\end{array}$ & $\begin{array}{l}\text { A Lexi-Search algorithm based on pattern } \\
\text { recognition technique is proposed. }\end{array}$ \\
\hline 16. & Latha $[7,8]$ & $\begin{array}{l}\text { Multi -Index } \\
\text { BTP }\end{array}$ & $\begin{array}{l}\text { A method based on the pattern recognition } \\
\text { technique coupled with the Lexi-search } \\
\text { approach is proposed. }\end{array}$ \\
\hline 17. & $\begin{array}{l}\text { Naganna[11],Naganna and } \\
\text { Murthy [12] }\end{array}$ & $\begin{array}{l}\text { Multi -Index } \\
\text { BTP }\end{array}$ & $\begin{array}{l}\text { A method to solve time dependent multi- } \\
\text { index BTP by a 'Lexi-Search' algorithm } \\
\text { based on 'Pattern Recognition Technique' is }\end{array}$ \\
\hline
\end{tabular}




\begin{tabular}{|l|l|l|l|}
\hline & & & proposed. \\
\hline 18. & Arora and Ahuja [1] & $\begin{array}{l}\text { Non Convex } \\
\text { BTP }\end{array}$ & $\begin{array}{l}\text { A fractional BTP was formed by the authors } \\
\text { whose feasible solution was used to find the } \\
\text { optimal solution of the non convex BTP. }\end{array}$ \\
\hline
\end{tabular}

\section{References:-}

1. Arora, S. R., Ahuja, A. (2001): Non-Convex bulk transportation problem, International Journal of Management Science, Vol. 7, No. 2, pp. 59-71.

2. Babu, K. S., Murthy, M.S.(2010):An Efficient algorithm for variant Bulk Transportation Problem, International Journal of Engineering Science and technology, Vol.2, No.7, pp. 2595- 2600.

3. Bhatia, H. L.(1979): A Note on a Zero-One Time Minimizing transportation Problem, NZOR Vol. 7.

4. Bhavani(1997):Combinatorial Programming problems(TSP), M.Phil Thesis, SVU College of Engg., Tirupati, A.P., India .

5. Foulds, L. R., Gibbons, P. B.(1980):New Algorithms for The Bulk, Zero-One Time Mini-Max Transportation Model”, NZOR Vol. 8, No. 2.

6. Gupta, A., Verma, V., Puri, M. C,(1995): Time -Cost Trade-off Relations in Bulk Transportation Problems, Journal of Information \& Optimization Sciences. Vol. 16 , No. 2, pp. 317-325.

7. Latha, A. V.(2013): Multi commodity Bulk Transportation Problem, International Journal of Research in Mathematics \& Computation, Vol. 1, No. 2, pp. 18-33 .

8. Latha, A. V.(2013): Three Dimensional Time Minimization Bulk transportation Problem, International Journal of Research in Mathematics \& Computation Vol. 1, No. 1, pp. 26-40.

9. Maio, A. D., Roveda, C.(1971) An all Zero -One Algorithm for a certain class of Transportation problems, Operations Research Vol.19, pp.1406-1418.

10. Murthy, M. S.(1976): A Bulk Transportation problem, Opsearch, Vol.13, pp.143-155.

11. Naganna, B.(2007): Operations Research. Ph.D Thesis, S.V. University, Tirupati, India((2007).

12. Naganna, B., Murthy, M. S.(2015): Time Dependent Bulk Transportation Problem, International Journal of Mathematics Research, Vol. 7, No. 2, pp. 159-166.

13. Prakash, S., Kumar, P., Prasad, B.V.N.S., Gupta, A.(2008):Pareto Optimal solutions of a cost - time trade-off Bulk Transportation problem, Eur. J. Oper. Res, Vol.188, pp. 85-110.

14. Prakash, S., Ram, P. P(1995). A bulk transportation problem with objectives to minimize total cost and duration of transportation, The Mathematics Student, Vol.64, pp. 206-214.

15. Prakash, S., Saluja, R. K., Singh, P.(2014):Pareto Optimal solutions to the Cost-Time Trade-Off Bulk Transportation Problem through a Newly Evolved Efficacious Novel algorithm, Journal of Data and Information Processing, Vol.2, No. 2, pp.13-25.

16. Prakash, S., Sharma, M. K., Singh, A.(2009):An Efficient Heuristic for Multi-Objective Bulk Transportation Problem, IEEE, pp. 1005-1009.

17. Purusotham, S., Murthy, M. S.(2011): An exact algorithm for Multi-Product Bulk Transportation problems, International Journal on Computer Science and Engineering, Vol.3, No.9 .

18. Srinivisan, V., Thompson, G.L.(1973): An Algorithm for assigning users to sources in a special class of transportation problems, Operations Research, Vol. 2, pp.284-295.

19. Verma, V., Puri, M.C.(1996): A branch and bound method for cost minimizing bulk transportation problem, Opsearch, Vol.33, No.3, pp.145-161. 